\title{
Erratum to: Natural Products as Antiparasitic Agents
}

Lucie Paloque, Asih Triastuti, Geneviève Bourdy

and Mohamed Haddad

\section{Erratum to:}

Chapter 9 in: J.-M. Mérillon and C. Rivière (eds.),

Natural Antimicrobial Agents, Sustainable

Development and Biodiversity 19, https://doi.org/10.1007/978-3-319-67045-4_9

In the original version of the book, the title of Chapter 9 has been changed from "Insecticidal and Antimalarial Properties of Plants: A Review" to "Natural Products as Antiparasitic Agents". The erratum chapter and the book have been updated with the change. 